\title{
BMJ Open Associations between blood cadmium levels and cognitive function in a cross- sectional study of US adults aged 60 years or older
}

\author{
Hongyu Li, ${ }^{1}$ Zhihui Wang, ${ }^{1}$ Zhen Fu, ${ }^{1}$ Mingming Yan, ${ }^{1}$ Nanjin Wu, ${ }^{1}$ Hongyan $\mathrm{Wu},{ }^{2}$ \\ Ping Yin ${ }^{1}$
}

To cite: Li H, Wang Z, Fu Z, et al. Associations between blood cadmium levels and cognitive function in a cross-sectional study of US adults aged 60 years or older. BMJ Open 2018;8:e020533. doi:10.1136/ bmjopen-2017-020533

- Prepublication history for this paper is available online. To view these files, please visit the journal online (http://dx.doi. org/10.1136/bmjopen-2017020533).

$\mathrm{HL}$ and ZW contributed equally.

Received 9 November 2017 Revised 12 February 2018 Accepted 23 February 2018

Check for updates

${ }^{1}$ Department of Epidemiology and Biostatistics and State Key Laboratory of Environment Health, Huazhong University of Science and Technology, Wuhan, China

${ }^{2}$ Department of Nursing, Union Hospital, Huazhong University of Science and Technology, Wuhan, China

\section{Correspondence to}

Dr Ping Yin;

pingyin2000@126.com and

Hongyan Wu;

wuhongyanbj@163.com

\section{ABSTRACT}

Objectives The relationship between cadmium exposure and cognition has been well studied in children. However, the association between environmental cadmium exposure and cognitive function has not been researched extensively in older adults. Our goal was to evaluate the association between cognitive function and blood cadmium levels in US adults aged 60 years or older.

Design A cross-sectional study.

Setting The US National Health and Nutrition Examination Survey (NHANES).

Participants A total of 2068 adults aged 60 years or older who completed four cognitive assessment tests and blood cadmium detection in two waves of NHANES (2011-2014). Main outcome measures Cognitive assessment was conducted by household interview or at a Mobile Examination Center (MEC) using the Consortium to Establish a Registry for Alzheimer's Disease (CERAD) Word List Learning Test, the CERAD Word List Recall Test, the Animal Fluency Test and the Digit Symbol Substitution Test (DSST). We created a composite cognitive z-score to represent global cognitive function.

Results The median blood cadmium concentration in the study participants was $0.35 \mu \mathrm{g} / \mathrm{L}$, and the IQR was $0.24-0.56 \mu \mathrm{g} / \mathrm{L}$. In linear regression analyses, adjusting for demographics, behaviour and medical history, blood cadmium as a continuous variable was inversely associated with the composite $z$-score $(\mu \mathrm{g} / \mathrm{L}, \beta=-0.11$, $95 \% \mathrm{Cl}-0.20$ to -0.03$)$. Similarly, there was a significant association between quartiles of blood cadmium and composite z-score, with somewhat lower scores in the upper quartile of exposure (blood cadmium $\geq 0.63 \mu \mathrm{g} / \mathrm{L}$ ) compared with those in the lower quartile of exposure (blood cadmium $<0.25 \mu \mathrm{g} / \mathrm{L})(\mu \mathrm{g} / \mathrm{L}, \beta=-0.14,95 \% \mathrm{Cl}$ -0.25 to -0.03 ), and there was a trend by quartiles of blood cadmium $(\mathrm{P}<0.0001)$.

Conclusions Our findings suggest that increased blood cadmium is associated with worse cognitive function in adults aged 60 years or older in the USA.

\section{INTRODUCTION}

The population is ageing rapidly worldwide, and the number of older persons-those aged 60 years or over-is expected to more
Strengths and limitations of this study

- We created a composite cognitive z-score representing global cognitive function to minimise the floor or ceiling effect of a single cognitive test and control for a range of factors that are known to affect cognitive function in our models.

- Our sample is very large and representative. Therefore, the association between cognitive function and cadmium exposure is more reliable.

- This study is cross-sectional, which restricts our assessments of the temporal relationships of the associations.

than double by 2050 and to more than triple by 2100 , increasing from 962 million globally in 2017 to 2.1 billion in 2050 and 3.1 billion in 2100. ${ }^{1}$ Age-related progressive cognitive decline will be a major public health challenge. It is estimated that, in the USA, approximately $36 \%$ of those over age 70 years are cognitively impaired, ${ }^{2}$ and 5.1 million elderly people have dementia, ${ }^{3}$ with an expected doubling by $2050{ }^{4}$

Cadmium is a heavy metal in the Earth's crust. Food and tobacco smoke are the main sources of cadmium in the body. Cadmium exerts its toxic effects on the kidneys and bone and on the central nervous system. Animal experiments revealed that cadmium can be transported directly from the olfactory epithelium to the central nervous system, bypassing the blood-brain barrier (BBB).$^{5}$ Additionally, a study showed that rats exposed to $10 \mathrm{ppm}$ cadmium $\left(\mathrm{CdCl}_{2}\right.$ salt $)$ in drinking water for 90 days had enhanced fluorescent dye permeability to the brain. The observed alteration in BBB permeability has been found to be coupled with a widespread depletion in free radical scavenging enzyme activities and other antioxidants in microvessels. ${ }^{6}$ In addition to increasing the permeability of 
the $\mathrm{BBB}$, cadmium has also been shown to accumulate in the choroid plexus, which is an important component of the BBB that can directly damage the general plexus structure, or selectively impair critical regulatory mechanisms. ${ }^{7}$ López et al ${ }^{8}$ reported that rat brain cortical neurons placed in serum-free medium containing $10 \mu \mathrm{m}$ cadmium had a large amount of neuronal apoptosis and axon disappearance after 24 hours. An in vitro study also confirmed that the cerebral cortical neurons exposed to $5 \mu \mathrm{m}, 10 \mu \mathrm{m}$ or $20 \mu \mathrm{m}$ cadmium are targets of cadmium toxicity. ${ }^{9}$ In children, the negative effects of cadmium on cognition have been extensively reported. ${ }^{10-13}$ However, the relationship between cadmium exposure and cognitive function in the elderly is unclear so far. In a cross-sectional study of 125 older people (age range 50-82 years) in Brazil, blood cadmium (mean, $0.90 \mu \mathrm{g} / \mathrm{L}$ ) was negatively associated with working memory capacity. ${ }^{14} \mathrm{~A}$ Chinese cohort study of 188 elderly individuals also reported a negative relationship between plasma cadmium levels (mean, $1.75 \mu \mathrm{g} / \mathrm{L}$ ) and cognitive scores. ${ }^{15}$ However, other studies failed to find a significant association between cadmium and neurocognitive test scores in older adults. ${ }^{16-18}$ Therefore, we analysed a large dataset of non-institutionalised civilians in the US aged 60 years or over from the continuous National Health and Nutrition Examination Survey (NHANES 2011-2014) to reveal the relationship between cadmium exposure and cognitive function.

\section{METHODS}

\section{Data sources and study population}

NHANES is a complex, multistage survey of non-institutionalised civilians in the USA that combines interviews and physical examinations. The interview includes demographic, socioeconomic, dietary and health-related questions. The examination component consists of medical, dental and physiological measurements, as well as laboratory tests administered by highly trained medical personnel. ${ }^{19}$ Weights are computed to arrive at a sample that is representative of the US population. We merged two cycles, 2011-2012 and 2013-2014, for this analysis. In this study, our research subjects were older adults aged 60 years or above. Respectively, 1687 and 1785 older adults aged $\geq 60$ years participated in the cognitive function test in the 2011-2012 and 2013-2014 cycles. Excluding participants who did not complete cognitive testing or blood cadmium measurement, a total of 2068 older adults were included in our analysis.

\section{Cognitive assessment}

Cognitive assessment was conducted in a household interview or at a Mobile Examination Center (MEC) using the Consortium to Establish a Registry for Alzheimer's Disease (CERAD) Word List Learning Test, the CERAD Word List Recall Test, the Animal Fluency test and the Digit Symbol Substitution Test (DSST). The CERAD Word List Learning test and the CERAD Word List Recall test were designed to assess immediate and delayed learning ability for new verbal information..$^{20}$ For the learning trials, participants were instructed to read aloud 10 unrelated words, one at a time, as they were presented. Immediately following the presentation of the words, participants recalled as many words as possible. In each of the three learning trials, the order of the 10 words is changed. The delayed word recall occurred after the other two cognitive exercises (Animal Fluency and DSST) were completed (approximately $8-10 \mathrm{~min}$ from the start of the word learning trials). The maximum score possible on each trial is 10. The Animal Fluency test examines categorical verbal fluency, ${ }^{21}$ a component of executive function in which participants were asked to name as many animals as possible in $1 \mathrm{~min}$. The DSST, a performance module from the Wechsler Adult Intelligence Scale (WAIS III), is used to assess processing speed, sustained attention and working memory. ${ }^{22}$ The exercise was conducted using a paper form that has a key at the top containing nine numbers paired with symbols. Participants have 2 min to copy the corresponding symbols in the 133 boxes that adjoin the numbers. The score is the total number of correct matches. Higher scores represent better cognitive function for all tests.

\section{Measurement of blood cadmium levels}

Blood samples were collected from participants by venipuncture in prescreened phials or vacuum tubes. After collection, the samples were transported and stored at a temperature of $4^{\circ} \mathrm{C}$ until receipt by the processing laboratory; the samples were then kept at $-20^{\circ} \mathrm{C}$ until analysis. Whole blood cadmium concentrations were determined using inductively coupled plasma mass spectrometry after a simple dilution sample preparation step. Further methodological details on the laboratory analyses are described elsewhere. ${ }^{23} 24$ The limits of detection (LODs) were $0.16 \mu \mathrm{g} / \mathrm{L}$ (NHANES 2011-2012) and $0.10 \mu \mathrm{g} / \mathrm{L}$ (NHANES 2013-2014). In cases where the result was below the limit of detection, the value was the detection limit divided by the square root of 2. A total of $107(5 \%)$ participants had measurements below the LOD.

\section{Covariates}

We included a variety of covariates based on previous research ${ }^{1415}$ in this study that are thought to be related to cognitive function and/or cadmium exposure: race-ethnicity (Mexican American/other Hispanic, non-Hispanic white, non-Hispanic black and other race), age (continuous variable), education level (<high school, high school and $>$ high school), poverty-income ratio (ratio of family income to poverty, $\leq 0.99$ and $\geq 1.00$ ), gender (male and female), marital status (married/living with partner, widowed/divorced/separated and never married), tobacco smoking (smoked at least 100 cigarettes in life and smoke now as current, smoked at least 100 cigarettes in life but does not smoke now as former, and smoked less than 100 cigarettes in life and not smoke now as never), alcohol consumption ( $<12$ drinks/year and $\geq 12$ drinks/ year), diabetes (yes and no), hypertension (yes and no), 
stroke (yes and no) and coronary heart disease (yes and no).

\section{Statistical analyses}

We used SAS V.9.2 for statistical analyses. Following the NHANES Analytical Guidelines, ${ }^{25}$ the MEC exam sample weights (WTMEC2YR) were used for analyses. Since we merged the 2011-2012 and 2013-2014 survey cycles, weights (WTMEC4YR) for combined NHANES survey cycles were calculated according to the NHANES file. ${ }^{25}$ Survey procedures were used to take the complex, multistage sampling design of NHANES into account. Because of the wide range of cognitive function in the elderly population, individual cognitive tests are subject to floor and ceiling effects. To minimise such effects, we created a composite cognitive z-score by using the average of the standardised scores of the four cognitive tests (CERAD Word List Learning Test, CERAD Word List Recall Test, Animal Fluency Test and DSST). The Kolmogorov-Smirnov test was used to test the normality assumption of the composite z-score. Descriptive statistics for our study population including proportions, means and percentiles were calculated. Univariate analyses of the association between the covariates and composite z-score were performed by univariate linear regression. Significant covariates in univariate analyses were included in the multiple linear regression. The multiple linear regression models were used to assess the association between blood cadmium as a continuous variable and composite z-score adjusted for age, gender, ethnicity, education, poverty-income ratio, marital status, alcohol consumption, diabetes, hypertension, stroke and coronary heart disease. In addition, we evaluated the association between quartiles of blood cadmium levels and composite z-scores. Due to the large impact of stroke on cognitive function, we conducted sensitivity analyses with and without individuals who had suffered a stroke. In each model, those who had missing data on covariates were excluded from the multiple linear regression. Statistical tests for linear trends were conducted by modelling quartiles as an ordinal variable using integer values and $\mathrm{p}$ value for trend based on the Wald test. P values $<0.05$ were considered statistically significant.

\section{RESULTS}

Data from four cognitive function tests were available for $2934(84.50 \%)$ of the 3472 participants evaluated. Blood cadmium data were available for $2068(70.48 \%)$ of these people. Study participants were on average approximately 69.14 years old. The composite z-score had a normal distribution $(\mathrm{P}=0.1273)$ and ranged from -2.53 to 2.50 (mean, 0.24 ; SE 0.04 ), with lower scores indicating worse cognitive function. The median blood cadmium concentration in the study participants was $0.35 \mu \mathrm{g} / \mathrm{L}$, and the IQR was $0.24-0.56 \mu \mathrm{g} / \mathrm{L}$. The demographic characteristics of those who completed the CERAD Word List Learning test, the CERAD Word List Recall test, the Animal Fluency test and the Digital Symbol Substitution test and had blood cadmium measures are presented in table 1 . All covariates besides tobacco smoking were associated with the composite z-score in the univariate analyses (table 2).

Blood cadmium as a continuous variable was inversely associated with the composite z-score in unadjusted model $1(\mu \mathrm{g} / \mathrm{L}, \beta=-0.19,95 \% \mathrm{CI}-0.29$ to -0.08$)$ (table 3$)$, and the association was also significant in model 2 adjusted for age, gender, ethnicity, education, poverty-income ratio and marital status ( $\mu \mathrm{g} / \mathrm{L}, \beta=-0.09,95 \% \mathrm{CI}-0.18$ to -0.01 ) (table 3). In addition, the association still existed in model 3 adjusted for age, gender, ethnicity, education, poverty-income ratio, marital status and alcohol consumption ( $\mu \mathrm{g} / \mathrm{L}, \beta=-0.11,95 \%$ CI -0.19 to -0.02 ) (table 3 ). Then, we adjusted for diabetes, hypertension, stroke and coronary heart disease in model 4 , and the association was significant as before $(\mu \mathrm{g} / \mathrm{L}, \beta=-0.11$, $95 \%$ CI -0.20 to -0.03 ) (table 3 ).

Table 5 presents the results of sensitivity analyses. Excluding individuals who suffered a stroke, blood cadmium as a continuous variable was also inversely associated with the composite z-score adjusted for age, gender, ethnicity, education, poverty-income ratio, marital status, alcohol consumption, diabetes, hypertension and coronary heart disease $(\mu \mathrm{g} / \mathrm{L}, \beta=-0.12$, $95 \%$ CI -0.20 to -0.04$)$. Similarly, the highest quartile was inversely associated with the composite z-score $(\mu \mathrm{g} / \mathrm{L}$, $\beta=-0.13,95 \%$ CI -0.23 to -0.03$)$. The trend still existed moving from the lowest quartile to the highest quartile ( $p$ trend $=0.0107$ ).

\section{DISCUSSION}

In this study of US adults aged 60-80 years, we found a significant inverse association between blood cadmium levels and cognitive function scores, and this correlation did not change after controlling for potential confounding factors.

The average concentration of blood cadmium was $0.50 \mu \mathrm{g} / \mathrm{L}$ in our study. A study analysing data from the 1999-2004 US NHANES adults aged over 40 years found that the mean blood cadmium concentration was $0.59 \mu \mathrm{g} / \mathrm{L} \quad(0.54-0.63) .{ }^{26}$ The median (IQR) concentration of blood cadmium in our study was $0.35 \mu \mathrm{g} / \mathrm{L}$ (0.24-0.56). A cross-sectional study using data from the third US NHANES with adults over 60 years old found that the median (IQR) concentration of blood cadmium was $0.39 \mu \mathrm{g} / \mathrm{L}(0.29-0.49) .{ }^{27}$ Thus, it can be seen that the level of blood cadmium in this study is consistent with previous studies.

The association between cadmium and children's IQ has been recognised in previous studies. ${ }^{10} 1128$ So far, however, the evidence for the relationship between cadmium and cognitive function in elderly populations has been limited and inconclusive. There are some studies whose results are consistent with the current study. For example, a Chinese study of elderly persons aged 65 years or older found a significant association between increased 
Open Access

Table 1 Characteristics of the study population $(n=2068)$

\begin{tabular}{|c|c|c|c|c|c|c|c|c|}
\hline Variables & $\mathbf{N}$ & $\begin{array}{l}\text { Weighted } \\
\text { sample }\end{array}$ & $(\%)^{\star}$ & Variables & $\mathbf{N}$ & $\begin{array}{l}\text { Weighted } \\
\text { sample }\end{array}$ & Mean (SE)* & Median (IQR)* \\
\hline Gender & & & & Age (year) & 2068 & 38452144 & $69.14(0.24)$ & $67.66(62.89-73.83)$ \\
\hline Male & 1011 & 17508127 & 45.53 & Blood cadmium ( $\mu \mathrm{g} / \mathrm{L})$ & 2068 & 38452144 & $0.50(0.02)$ & $0.35(0.24-0.56)$ \\
\hline Female & 1057 & 20944017 & 54.47 & CERAD learning score & 2068 & 38452144 & $19.48(0.27)$ & $19.00(16.27-22.16)$ \\
\hline Race-ethnicity & & & & CERAD recall score & 2068 & 38452144 & $6.09(0.10)$ & $5.77(4.12-7.34)$ \\
\hline Mexican American/other Hispanic & 385 & 2618094 & 6.81 & Animal Fluency score & 2068 & 38452144 & $18.14(0.21)$ & $17.38(13.51-21.00)$ \\
\hline Non-Hispanic white & 988 & 30935957 & 80.45 & DSST score & 2068 & 38452144 & $52.20(0.66)$ & $52.68(40.09-63.92)$ \\
\hline Non-Hispanic black & 491 & 2980219 & 7.75 & z-score & 2068 & 38452144 & $0.24(0.04)$ & $0.28(-0.28$ to 0.80$)$ \\
\hline Other race & 204 & 1917874 & 4.99 & & & & & \\
\hline \multicolumn{9}{|l|}{ Education level } \\
\hline$<$ High school & 531 & 6133440 & 15.95 & & & & & \\
\hline High school & 490 & 8783404 & 22.84 & & & & & \\
\hline >High school & 1046 & 23530632 & 61.19 & & & & & \\
\hline Missing & 1 & 4669 & 0.01 & & & & & \\
\hline \multicolumn{9}{|l|}{ Poverty-income ratio } \\
\hline$\leq 0.99$ & 333 & 3298332 & 8.58 & & & & & \\
\hline$\geq 1$ & 1550 & 32672780 & 84.97 & & & & & \\
\hline Missing & 185 & 2481032 & 6.45 & & & & & \\
\hline \multicolumn{9}{|l|}{ Marital status } \\
\hline Married/living with partner & 1201 & 25353317 & 65.93 & & & & & \\
\hline Widowed/divorced/separated & 742 & 11403761 & 29.66 & & & & & \\
\hline Never married & 124 & 1689836 & 4.39 & & & & & \\
\hline Missing & 1 & 5230 & 0.01 & & & & & \\
\hline \multicolumn{9}{|l|}{ Tobacco smoking } \\
\hline Current & 257 & 3965965 & 10.31 & & & & & \\
\hline Former & 784 & 15571098 & 40.49 & & & & & \\
\hline Never & 1026 & 18907598 & 49.17 & & & & & \\
\hline Missing & 1 & 7483 & 0.02 & & & & & \\
\hline \multicolumn{9}{|l|}{ Alcohol consumption } \\
\hline$\geq 12$ drink/year & 1397 & 27847784 & 72.42 & & & & & \\
\hline$<12$ drink/year & 640 & 10098855 & 26.26 & & & & & \\
\hline Missing & 31 & 505505 & 1.31 & & & & & \\
\hline \multicolumn{9}{|l|}{ Diabetes } \\
\hline Yes & 472 & 7293920 & 18.97 & & & & & \\
\hline No & 1508 & 29747613 & 77.36 & & & & & \\
\hline Missing & 88 & 1410611 & 3.67 & & & & & \\
\hline \multicolumn{9}{|l|}{ Hypertension } \\
\hline Yes & 1262 & 21869127 & 56.87 & & & & & \\
\hline No & 804 & 16514849 & 42.95 & & & & & \\
\hline Missing & 2 & 68168 & 0.18 & & & & & \\
\hline \multicolumn{9}{|l|}{ Stroke } \\
\hline Yes & 138 & 2341705 & 6.09 & & & & & \\
\hline No & 1926 & 36057144 & 93.77 & & & & & \\
\hline Missing & 4 & 53295 & 0.14 & & & & & \\
\hline \multicolumn{9}{|l|}{ Coronary heart disease } \\
\hline Yes & 172 & 3086811 & 8.03 & & & & & \\
\hline No & 1886 & 35263550 & 91.71 & & & & & \\
\hline Missing & 10 & 101784 & 0.26 & & & & & \\
\hline
\end{tabular}

*Weighted percentage, mean, SE, median and IQR.

CERAD, Consortium to Establish a Registry for Alzheimer's Disease; DSST, Digit Symbol Substitution Test. 
Table 2 Univariate analyses of the association between $z$-score and covariates $(n=2068)$ : NHANES 2011-2014

\begin{tabular}{|c|c|c|c|}
\hline Variables & $\begin{array}{l}\text { Score } \\
\text { mean }(\mathrm{SE})^{*}\end{array}$ & F value & $P$ values \\
\hline Gender & & 14.85 & 0.0005 \\
\hline Male & $0.16(0.05)$ & & \\
\hline Female & $0.32(0.04)$ & & \\
\hline Age (year) & - & $-20.39 \dagger$ & $<0.0001$ \\
\hline Race-ethnicity & & 25.11 & $<0.0001$ \\
\hline $\begin{array}{l}\text { Mexican American/other } \\
\text { Hispanic }\end{array}$ & $-0.28(0.05)$ & & \\
\hline Non-Hispanic white & $0.33(0.05)$ & & \\
\hline Non-Hispanic black & $-0.13(0.05)$ & & \\
\hline Other race & $0.14(0.06)$ & & \\
\hline Education level & & 79.48 & $<0.0001$ \\
\hline$<$ High school & $-0.34(0.05)$ & & \\
\hline High school & $0.05(0.05)$ & & \\
\hline$>$ High school & $0.47(0.04)$ & & \\
\hline Poverty-income ratio & & 68.63 & $<0.0001$ \\
\hline$\leq 0.99$ & $-0.30(0.06)$ & & \\
\hline$\geq 1$ & $0.31(0.04)$ & & \\
\hline Material status & & 7.46 & 0.0022 \\
\hline Married/living with partner & $0.31(0.05)$ & & \\
\hline Widowed/divorced/separated & $0.10(0.04)$ & & \\
\hline Never married & $0.31(0.12)$ & & \\
\hline Alcohol consumption & & 27.46 & $<0.0001$ \\
\hline$<12$ drinks/year & $0.04(0.03)$ & & \\
\hline$\geq 12$ drinks/year & $0.32(0.05)$ & & \\
\hline Tobacco smoking & & 1.95 & 0.1587 \\
\hline Current & $0.15(0.08)$ & & \\
\hline Former & $0.22(0.04)$ & & \\
\hline Never & $0.29(0.05)$ & & \\
\hline Hypertension & & 25.79 & $<0.0001$ \\
\hline Yes & $0.15(0.04)$ & & \\
\hline No & $0.38(0.04)$ & & \\
\hline Diabetes & & 26.98 & $<0.0001$ \\
\hline Yes & $-0.03(0.04)$ & & \\
\hline No & $0.31(0.05)$ & & \\
\hline Stroke & & 13.24 & 0.0010 \\
\hline Yes & $-0.16(0.10)$ & & \\
\hline No & $0.27(0.04)$ & & \\
\hline Coronary heart disease & & 28.41 & $<0.0001$ \\
\hline Yes & $-0.11(0.07)$ & & \\
\hline No & $0.28(0.04)$ & & \\
\hline
\end{tabular}

*Weighted mean and SE.

tt value.

NHANES, National Health and Nutrition Examination Survey.

blood cadmium levels and worse cognitive function after adjustment for age, sex, education, body mass index and apolipoprotein E genotype. ${ }^{15}$ Its sample size was 188 , and six cognitive assessment tests are used comprehensively to evaluate cognitive function. Another study on people aged 50-82 years with 135 individuals in Brazil found that high blood cadmium concentration alone and in combination with elevated blood lead concentration was associated with an important cognitive construct, poor working memory capacity, after adjustment for age, sex, income, haemoglobin and haematocrit. ${ }^{14}$ However, a Korean study suggested that serum cadmium levels were significantly higher in the Alzheimer's disease (AD) group without age adjustment but was not significant after adjustment for age ${ }^{16}$ It was a small sample of 207 individuals (89 patients with $\mathrm{AD}$ and 118 cognitively normal people), and it only adjusted for age and years of education to evaluate the association between cadmium and cognitive function, which can affect the reliability of the results. The reason for the difference in the above study results may be due to different biological samples in different countries, sample sizes and covariates adjusted in the models. The sample sizes of these studies are small, and only demographic factors are included in their models. In contrast, our sample size was larger with 2068 individuals. In addition to demographics, we adjusted for more factors (alcohol consumption and medical history) that have been reported to be related to cadmium and/or cognitive function. ${ }^{29-34}$ Therefore, the results are probably more stable and reliable.

The exact mechanisms with which cadmium exposure affects cognition have yet not to be revealed. The possible mechanisms are as follows. First, studies suggest that cadmium exposure can increase the activity of acetylcholinesterase, which can hydrolyse acetylcholine and reduce its concentration,,$^{35}$ and there is a positive correlation between acetylcholine deficiency and cognitive impairment. ${ }^{36}$ Moreover, studies show that cadmium induces the formation of reactive oxygen species (ROS) ${ }^{37} 38$ Excessive ROS can cause superoxide reaction of nucleic acid and protein and make the chromatin concentrate and fragment, also cause inflammation, eventually leading to neuronal damage and death. Other studies suggest that the cytotoxicity of cadmium can be attributable to the interference of cadmium with intracellular cation homoeostasis. ${ }^{39} 40$ Cadmium can upregulate the internal concentration of calcium in neurons, thereby affecting the synthesis and release of neurotransmitters, eventually leading to neuronal dysfunction. ${ }^{40}$

There are several strengths and limitations in our study. First, we have a large sample size and good representativeness of the subjects. Second, we created a composite cognitive z-score representing global cognitive function to minimise the floor or ceiling effect of a single cognitive test and adjusted for multiple potential confounders in our models. Third, NHANES did not include an occupation code to screen for cadmium-exposure jobs such as smelting, electroplating, pigment manufacture and application, and alkaline battery manufacturing. Fourth, due to the lack of laboratory indicators such as cotinine, we only used self-reported smoking in analyses, which could cause some bias. Fifth, we created a composite cognitive 


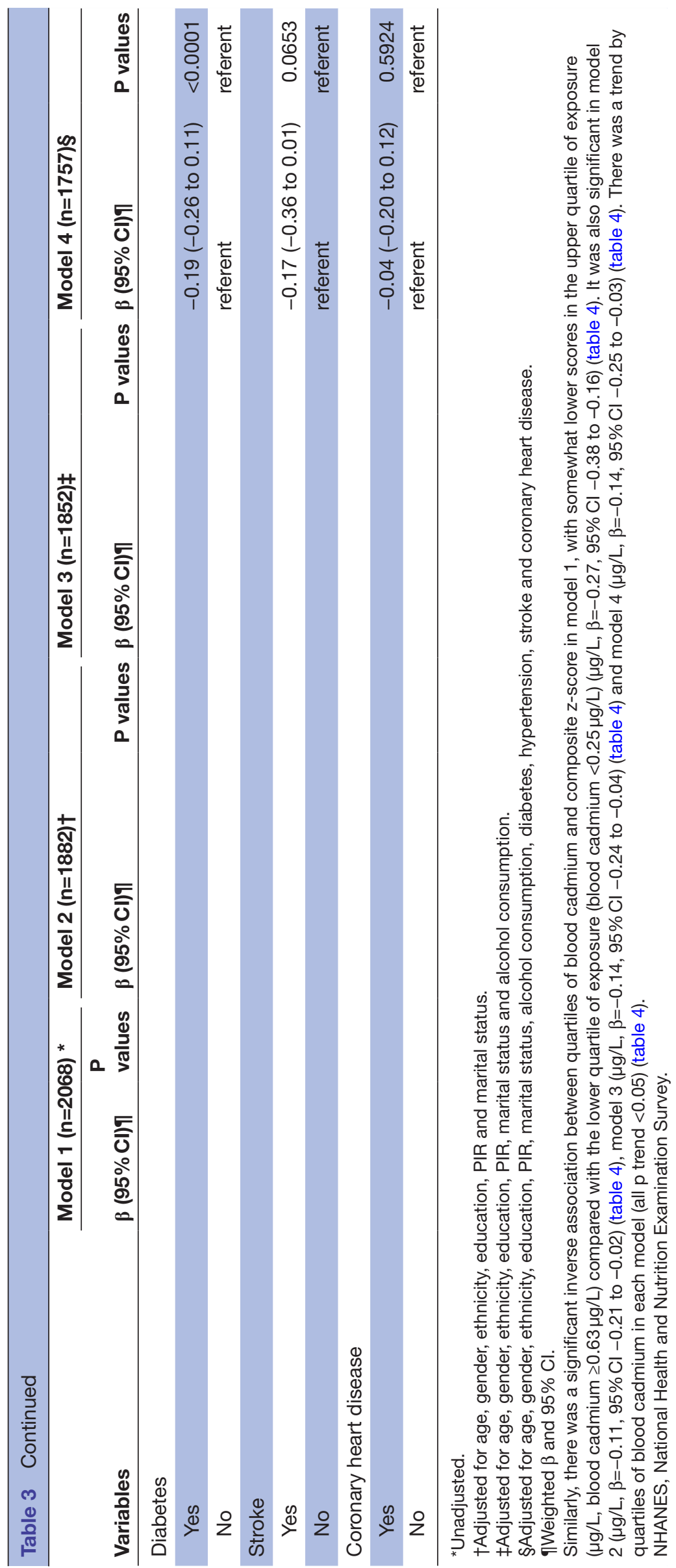

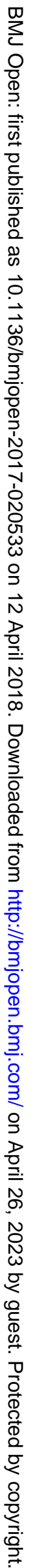




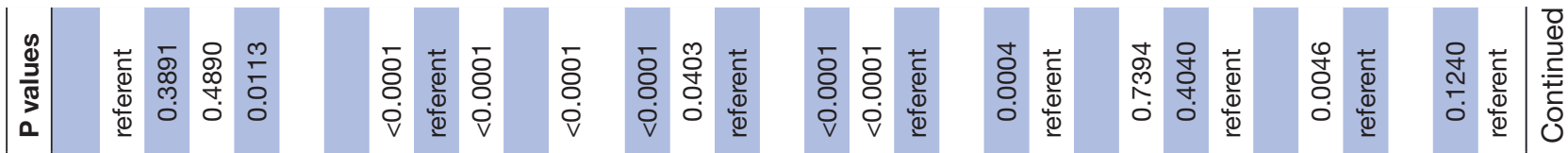

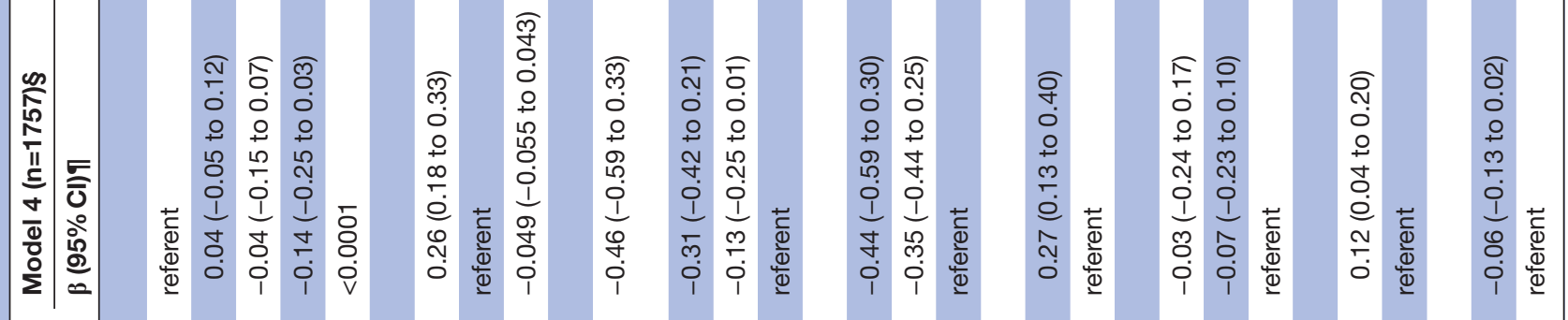

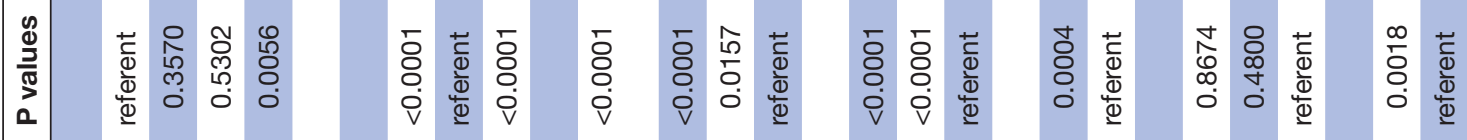

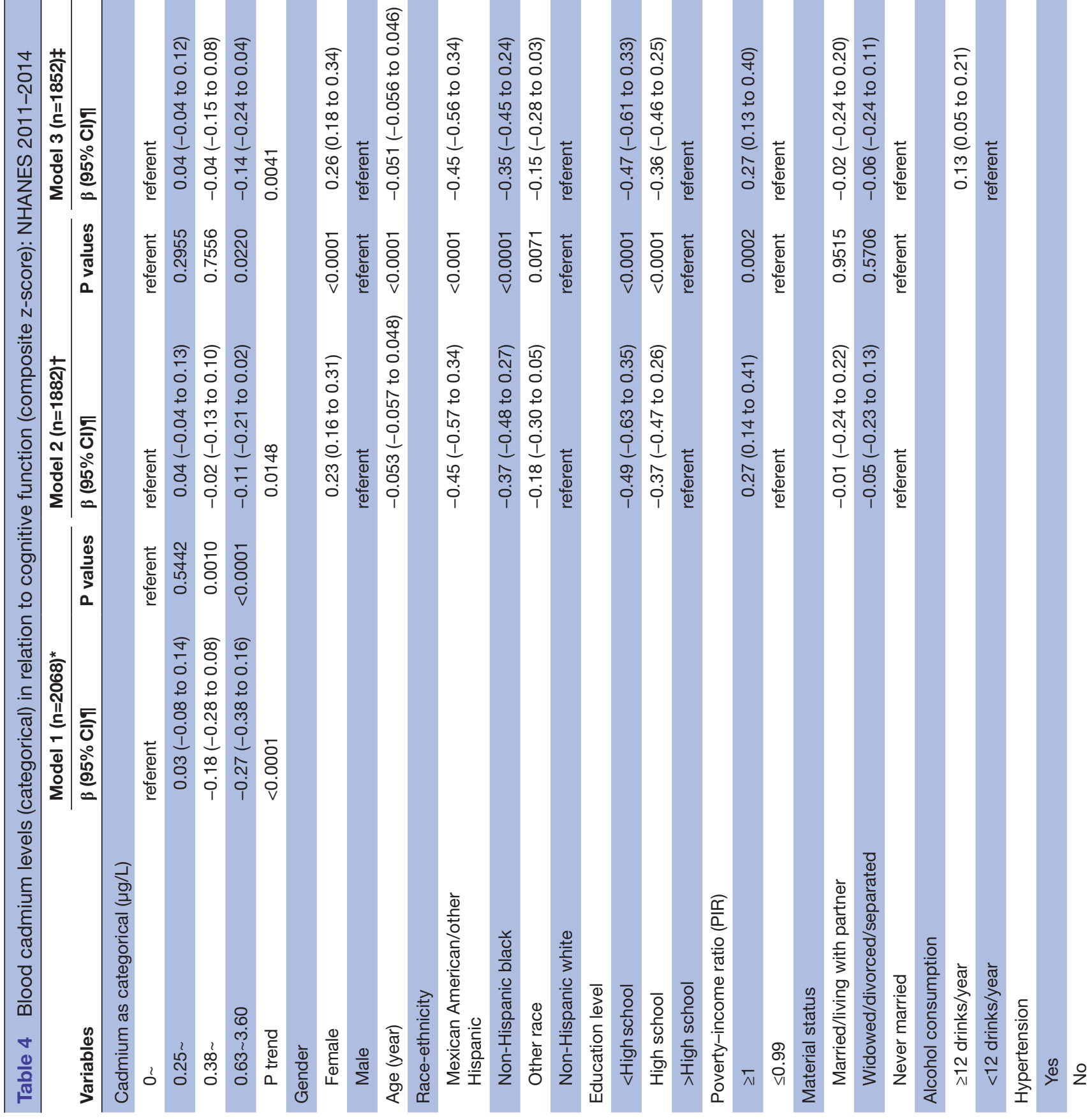


Table 5 Association between blood cadmium levels and cognitive function (composite $z$-score) excluding individuals who suffered a stroke $(n=1636)$ : NHANES 2011-2014*

\begin{tabular}{llll}
\hline Blood cadmium $(\boldsymbol{\mu g} / \mathbf{L})$ & $\boldsymbol{\beta}(\mathbf{9 5 \%} \mathbf{C l}) \dagger$ & $\begin{array}{l}\mathbf{P} \\
\text { values }\end{array}$ & $\mathbf{P}$ trend \\
\hline Cadmium as continuous & $-0.12(-0.20$ to 0.04$)$ & 0.0060 & - \\
\hline Cadmium as categorical & & & \\
\hline 0 & referent & referent & 0.0107 \\
$0.25 \sim$ & $0.04(-0.05$ to 0.13$)$ & 0.3579 & \\
$0.38 \sim$ & $-0.04(-0.15$ to 0.08$)$ & 0.5067 & \\
$0.63 \sim 3.60$ & $-0.13(-0.23$ to 0.03$)$ & 0.0159 & \\
\hline
\end{tabular}

*Adjusted for age, gender, ethnicity, education, PIR, marital status, alcohol consumption, diabetes, hypertension, and coronary heart disease.

†Weighted $\beta$ and $95 \% \mathrm{Cl}$.

NHANES, National Health and Nutrition Examination Survey.

z-score by using the average of the standardised scores of the four cognitive tests, which provided a more complete picture of the relationship between blood cadmium and cognitive function but limited us in explaining the practical meaning of the effect size. Nevertheless, this study is a cross-sectional study that restricted us in assessing the temporal relationships of the associations.

It has been found that gender, age, education level, race-ethnicity, poverty-income ratio, alcohol consumption and diabetes can contribute to cognitive function, and their effects should be considered in future research on the association between cadmium exposure and cognitive function. Through the results, we find that the regression coefficients change from positive to negative and decrease with the increase in blood cadmium, regardless of whether the difference is significant. There is a trend, to some extent, that can provide a basis for future studies.

The investigation of the inverse association between blood cadmium and cognitive function is very significant for putting forward some strategies towards delaying of cognitive function descending of older adults. Because cadmium is an accumulative poison, coming primarily from food and tobacco smoke, exposure can be modified through healthy eating and behavioural habits. Such changes will have a vital impact on the improvement of cognitive function in adults aged 60 years or older.

\section{CONCLUSIONS}

Our findings suggest that increasing blood cadmium is associated with worse cognitive function in older adults aged 60 years or older in the USA. The results need verification in other populations.

Contributors $\mathrm{HL}$ and $\mathrm{ZW}$ conceived and designed the study, analysed and interpreted the data and wrote the manuscript. ZF, MY and NW conducted data collection and statistical analyses. HW and PY reviewed the manuscript. All authors read and approved the final manuscript.

Funding This research received no specific grant from any funding agency in the public, commercial or not-for-profit sectors.

Competing interests None declared. 
Patient consent Obtained.

Ethics approval This study was approved by the National Center for Health Statistics Research ethics review board.

Provenance and peer review Not commissioned; externally peer reviewed.

Data sharing statement The NHANES data are publicly available at https://www. cdc.gov/nchs/nhanes/about_nhanes.htm.

Open Access This is an Open Access article distributed in accordance with the Creative Commons Attribution Non Commercial (CC BY-NC 4.0) license, which permits others to distribute, remix, adapt, build upon this work non-commercially, and license their derivative works on different terms, provided the original work is properly cited and the use is non-commercial. See: http://creativecommons.org/ licenses/by-nc/4.0/

(C) Article author(s) (or their employer(s) unless otherwise stated in the text of the article) 2018. All rights reserved. No commercial use is permitted unless otherwise expressly granted.

\section{REFERENCES}

1. United Nations. Ageing. http://www.un.org/en/sections/issues-depth/ ageing/index.html (accessed 10 Oct 2017).

2. Plassman BL, Langa KM, Fisher GG, et al. Prevalence of cognitive impairment without dementia in the United States. Ann Intern Med 2008;148:427-34.

3. Daviglus ML, Bell CC, Berrettini W, et al. NIH state-of-the-science conference statement: Preventing Alzheimer's disease and cognitive decline. NIH Consens State Sci Statements 2010;27:1-30.

4. Hebert LE, Weuve J, Scherr PA, et al. Alzheimer disease in the United States (2010-2050) estimated using the 2010 census. Neurology 2013;80:1778-83.

5. Bondier JR, Michel G, Propper A, et al. Harmful effects of cadmium on olfactory system in mice. Inhal Toxicol 2008;20:1169-77.

6. Shukla A, Shukla GS, Srimal RC. Cadmium-induced alterations in blood-brain barrier permeability and its possible correlation with decreased microvessel antioxidant potential in rat. Hum Exp Toxicol 1996;15:400-5.

7. Zheng W. Toxicology of choroid plexus: special reference to metalinduced neurotoxicities. Microsc Res Tech 2001;52:89-103.

8. López E, Figueroa S, Oset-Gasque MJ, et al. Apoptosis and necrosis: two distinct events induced by cadmium in cortical neurons in culture. Br J Pharmacol 2003;138:901-11.

9. Yuan $\mathrm{Y}$, Jiang $\mathrm{CY}, \mathrm{Xu} \mathrm{H}$, et al. Cadmium-induced apoptosis in primary rat cerebral cortical neurons culture is mediated by a calcium signaling pathway. PLoS One 2013;8:e64330.

10. Jeong KS, Park $\mathrm{H}$, Ha E, et al. Performance $\mathrm{IQ}$ in children is associated with blood cadmium concentration in early pregnancy. $J$ Trace Elem Med Biol 2015;30:107-11.

11. Kippler M, Tofail F, Hamadani JD, et al. Early-life cadmium exposure and child development in 5-year-old girls and boys: a cohort study in rural Bangladesh. Environ Health Perspect 2012;120:1462-8.

12. Rodríguez-Barranco M, Lacasaña M, Gil F, et al. Cadmium exposure and neuropsychological development in school children in southwestern Spain. Environ Res 2014;134:66-73.

13. Ciesielski T, Weuve J, Bellinger DC, et al. Cadmium exposure and neurodevelopmental outcomes in U.S. children. Environ Health Perspect 2012;120:758-63.

14. Souza-Talarico JN, Marcourakis T, Barbosa F, et al. Association between heavy metal exposure and poor working memory and possible mediation effect of antioxidant defenses during aging. Sci Total Environ 2017;575:750-7.

15. Gao S, Jin Y, Unverzagt FW, et al. Trace element levels and cognitive function in rural elderly Chinese. The journals of gerontology. Series A, Biological sciences and medical sciences 2008;63:635-41.

16. Park JH, Lee DW, Park KS, et al. Serum trace metal levels in Alzheimer's disease and normal control groups. Am J Alzheimers Dis Other Demen 2014;29:76-83.

17. Basun $H$, Lind $B$, Nordberg $M$, et al. Cadmium in blood in Alzheimer's disease and non-demented subjects: results from a populationbased study. Biometals: an international journal on the role of metal ions in biology, biochemistry, and medicine 1994;7:130-4.
18. Nordberg M, Winblad B, Basun H. Cadmium concentration in blood in an elderly urban population. Biometals 2000;13:311-7.

19. Balzano J, Chiaravalloti N, Lengenfelder J, et al. Does the scoring of late responses affect the outcome of the paced auditory serial addition task (PASAT)? Arch Clin Neuropsychol 2006;21:819-25.

20. Morris JC, Heyman A, Mohs RC, et al. The Consortium to Establish a Registry for Alzheimer's Disease (CERAD). Part I. Clinical and neuropsychological assessment of Alzheimer's disease. Neurology 1989;39:1159-65.

21. de Souza Fernandes DP, Canaan Rezende FA, Pereira Rocha G, et al. Effect of eicosapentaenoic acid and docosahexaenoic acid supplementations to control cognitive decline in dementia and alzheimer's disease: a systematic review. Nutr Hosp 2015;32:528-33.

22. Chaudhuri D, Majumder A, Misra AK, et al. Cadmium removal by Lemna minor and Spirodela polyrhiza. Int $J$ Phytoremediation 2014;16:1119-32.

23. CDC/National Center for Health Statistics. National Health and Nutrition Examination Survey 2011-2012. Laboratory Procedure Manuals. CDC. https://wwwn.cdc.gov/nchs/data/nhanes/2011-2012/ labmethods/pbcd_g_met_blood-metals.pdf (accessed 7 Dec 2017).

24. CDC/National Center for Health Statistics. National Health and Nutrition Examination Survey 2013-2014. Laboratory Procedure Manuals. CDC. https://wwwn.cdc.gov/nchs/data/nhanes/2013-2014/ labmethods/PbCd_H_MET.pdf (accessed 7 Dec 2017).

25. CDC/National Center for Health Statistics. National Health and Nutrition Examination Survey: Analytic Guidelines, 1999-2010.CDC. https://wwwn.cdc.gov/nchs/data/series/sr02_161.pdf (accessed 10 Oct 2017).

26. Min KB, Lee KJ, Park JB, et al. Lead and cadmium levels and balance and vestibular dysfunction among adult participants in the National Health and Nutrition Examination Survey (NHANES) 19992004. Environ Health Perspect 2012;120:413-7.

27. García-Esquinas E, Navas-Acien A, Pérez-Gómez B, et al. Association of lead and cadmium exposure with frailty in US older adults. Environ Res 2015;137:424-31.

28. Tian LL, Zhao YC, Wang XC, et al. Effects of gestational cadmium exposure on pregnancy outcome and development in the offspring at age 4.5 years. Biol Trace Elem Res 2009;132:51-9.

29. Heitland P, Köster HD. Biomonitoring of 37 trace elements in blood samples from inhabitants of northern Germany by ICP-MS. J Trace Elem Med Biol 2006;20:253-62.

30. Lyu J, Lee SH. Gender differences in the link between excessive drinking and domain-specific cognitive functioning among older adults. J Aging Health 2012;24:1380-98.

31. Li T, Xiang J, Bai J, et al. [The association of duration of hypertension and changes in cognitive function in hypertension patients]. Zhonghua Nei Ke Za Zhi 2014;53:278-82.

32. Nooyens AC, Baan CA, Spijkerman AM, et al. Type 2 diabetes and cognitive decline in middle-aged men and women: the Doetinchem Cohort Study. Diabetes Care 2010;33:1964-9.

33. Pendlebury ST. Dementia in patients hospitalized with stroke: rates, time course, and clinico-pathologic factors. Int J Stroke 2012;7:570-81.

34. Gayda M, Gremeaux V, Bherer L, et al. Cognitive function in patients with stable coronary heart disease: Related cerebrovascular and cardiovascular responses. PLoS One 2017;12:e0183791.

35. Jia JP, Jia JM, Zhou WD, et al. Differential acetylcholine and choline concentrations in the cerebrospinal fluid of patients with Alzheimer's disease and vascular dementia. Chin Med J 2004;117:1161-4.

36. Gonçalves JF, Nicoloso FT, da Costa P, et al. Behavior and brain enzymatic changes after long-term intoxication with cadmium salt or contaminated potatoes. Food Chem Toxicol 2012;50:3709-18.

37. Visa M, Duta A. Methyl-orange and cadmium simultaneous removal using fly ash and photo-Fenton systems. J Hazard Mater 2013;244245:773-9.

38. Son YO, Wang L, Poyil P, et al. Cadmium induces carcinogenesis in BEAS-2B cells through ROS-dependent activation of PI3K/AKT/GSK3// $\beta$-catenin signaling. Toxicol Appl Pharmacol 2012;264:153-60.

39. Kuang X, Fang Z, Wang S, et al. Effects of cadmium on intracellular cation homoeostasis in the yeast Saccharomyces cerevisiae. Toxicological \& Environmental Chemistry 2015;97:922-30.

40. Martelli A, Rousselet E, Dycke C, et al. Cadmium toxicity in animal cells by interference with essential metals. Biochimie 2006;88:1807-14. 